\title{
Análise da redução da alcalinidade de compósitos cimento-madeira em função da substituição parcial do cimento Portland por pozolanas
}

\author{
Analysis of the alkalinity reduction of the \\ wood-cement composites in the function \\ of the partial replacement of the Portland \\ cement by pozzolans
}

Adauto José Miranda de Lima ${ }^{1}$, Setsuo Iwakiri ${ }^{2}$

\footnotetext{
${ }^{1}$ Laboratório de Construção Civil - PPGCC/UTFPR, 81280-340, Curitiba, PR, Brasil.

${ }^{2}$ Laboratório de Painéis de Madeira - PPGEF/UFPR, 80210-170, Curitiba, PR, Brasil.

e-mail: adautojm@utfpr.edu.br, setsuo.ufpr@gmail.com
}

\begin{abstract}
RESUMO
O objetivo desta pesquisa foi avaliar a redução da alcalinidade de compósitos cimento-madeira, produzido com cimento Portland e partículas residuais de Pinus spp., em função da substituição gradual do cimento Portland pelas pozolanas sílica ativa (SA) metacaulim (MK), cinza volante (CV), escória de alto-forno (EAF), cinza de casca de arroz (CCA) e resíduo de cerâmica calcinada (RCC). Para tanto, foram produzidos corpos de prova cilíndricos, com diâmetro de $5 \mathrm{~cm}$, com compósitos com $100 \%$ de cimento Portland e partículas residuais de Pinus spp., adotados como referência e, com substituições parciais do cimento por 0\%, $5 \%, 10 \%, 15 \%$ e $20 \%$ de SA, $0 \%, 10 \%, 20 \%, 30 \%$ e $40 \%$ de MK, CV, CCA e RCC e $0 \%, 30 \%, 40 \%, 50 \%$ e $60 \%$ de EAF. O resíduo de Pinus spp. inicialmente passou por pré-tratamento tipo extração em água fria por um período de 24 horas para melhorar a compatibilidade com a matriz cimentícia. Na produção dos compósitos foi utilizado um aditivo superplastificante de $1^{a}$ geração, base de lignosulfonatos, naftalenos e melaninas em teores que variaram entre $0 \%$ a $7,8 \%$ do teor de cimento e das pozolanas utilizadas e cloreto de cálcio bi-hidratado $\left(\mathrm{CaCl}_{2} \cdot 2 \mathrm{H}_{2} \mathrm{O}\right)$ como aditivo acelerador de pega, em teores que variaram entre $0 \%$ a $4,5 \%$, calculados em massa em relação ao teor de cimento dos compósitos. Os compósitos ficaram em cura imersa por um período de 91 dias e após esse período foram moídos e adicionados a água deionizada, sendo o pH determinado através da solução de equilíbrio. Em relação ao compósito de Referência, que apresentou pH = 12,67, foram verificadas quedas significativas da alcalinidade dos compósitos estudados, em função da utilização das substituições parciais do cimento Portland, de $10,02 \%$ (20\% de SA, com 4,5\% de $\mathrm{CaCl}_{2} .2 \mathrm{H}_{2} \mathrm{O}$ e $4,4 \%$ de SP), $12,55 \%$ ( $40 \%$ de $\mathrm{MK}$, com $4,5 \%$ de $\mathrm{CaCl}_{2} \cdot 2 \mathrm{H}_{2} \mathrm{O}$ e $7,8 \%$ de SP), $5,13 \%$ (40\% de CV com $4,5 \%$ de $\left.\mathrm{CaCl}_{2} \cdot 2 \mathrm{H}_{2} \mathrm{O}\right), 3,87 \%\left(60 \%\right.$ de EAF com $4,5 \%$ de $\left.\mathrm{CaCl}_{2} \cdot 2 \mathrm{H}_{2} \mathrm{O}\right), 15,15 \%(40 \%$ de CCA, com $4,5 \%$ de $\mathrm{CaCl}_{2} \cdot 2 \mathrm{H}_{2} \mathrm{O}$ e $4,2 \%$ de SP) e $8,29 \%$ (40\% de RCC, com 4,5\% de $\mathrm{CaCl}_{2} .2 \mathrm{H}_{2} \mathrm{O}$ e $2,6 \%$ de SP).
\end{abstract}

Palavras-chave: Compósito cimento-madeira, Pinus spp., pozolanas, alcalinidade.

\section{ABSTRACT}

The objective of this research was to evaluate the alkalinity reduction of the wood-cement composites produced with Portland cement and residual particles of Pinus spp., as a function of the gradual replacement of the Portland cement by the pozzolans silica fume (SA) metakaolin (MK), fly ash (CV), blast slag furnace (EAF), rice husk ash (CCA) and calcined ceramic residue (RCC). For this, $5 \mathrm{~cm}$ diameter cylindrical specimens were produced with composites wiyh $100 \%$ Portland cement and residual Pinus spp. particles, adopted as reference and with partial cement replacements by $0 \%, 5 \%, 10 \%, 15 \%$ and $20 \%$ of SA, $0 \%, 10 \%$, $20 \%, 30 \%$ e $40 \%$ de MK, CV, CCA e RCC e $0 \%, 30 \%, 40 \%, 50 \%$ e $60 \%$ de EAF. The Pinus spp. residue initially underwent pre-treatment type extraction in cold water for a period of 24 hours to improve 
compatibility with the cementitious matrix. In the production of the composites a superplasticizer additive of 1 st generation was used, based on lignosulphonates, naphthalenes and melanins in contents ranging from $0.20 \%$ to $7.8 \%$ of the cement and pozzolan and content and hydrated calcium chloride $\left(\mathrm{CaCl}_{2} \cdot 2 \mathrm{H}_{2} \mathrm{O}\right)$ was used with accelerator additive in amounts ranging from $0 \%$ to $4.5 \%$ calculated in mass in relation to the cement content of the composites. The composites were immersed for a period of 91 days and after that period were grounded and added to the deionized water, and the $\mathrm{pH}$ was determined through the equilibrium solution. Significant reductions in the $\mathrm{pH}$ of the composites were determined in relation to the $\mathrm{pH}$ value of the reference composite (12.67) of the order of $10.02 \%$ (20\% de SA, with $4.5 \%$ of $\mathrm{CaCl}_{2} .2 \mathrm{H}_{2} \mathrm{O}$ and $4.4 \%$ of $\mathrm{SP}$ ), $12.55 \%$ ( $40 \%$ de $\mathrm{MK}$, with $4.5 \%$ of $\mathrm{CaCl}_{2} .2 \mathrm{H}_{2} \mathrm{O}$ and $7.8 \%$ of SP), $5.13 \%$ (40\% of CVwith $4.5 \%$ of $\mathrm{CaCl}_{2} .2 \mathrm{H}_{2} \mathrm{O}$ ), $3.87 \%$ (60\% of EAF with $4.5 \%$ of $\mathrm{CaCl}_{2} .2 \mathrm{H}_{2} \mathrm{O}$ ), $15.15 \%$ (40\% of CCA, with $4.5 \%$ of $\mathrm{CaCl}_{2} .2 \mathrm{H}_{2} \mathrm{O}$ and $4.2 \%$ of SP) and $8.29 \%$ (40\% of RCC, with $4.5 \%$ of $\mathrm{CaCl}_{2} .2 \mathrm{H}_{2} \mathrm{O}$ and $2.6 \%$ of SP).

Keywords: Cement-wood composites, Pinus spp., pozzolans, alkalinity.

\section{INTRODUÇÃO}

A crescente preocupação mundial com a sustentabilidade e a utilização de recursos naturais renováveis tem sido, cada vez mais, uma temática discutida pelas nações desenvolvidas e em desenvolvimento. A disposição final dos resíduos gerados em diversas atividades industriais apresenta sério problema para estes países.

Dentre os resíduos gerados pela indústria, muitos apresentam potencial para retornarem para a cadeia produtiva, dando origem a novos materiais, dentre eles pode-se citar os resíduos produzidos pela indústria madeireira. O Brasil é o quinto maior produtor agrícola do mundo e segundo o último levantamento do Sistema Nacional de Informações Florestais [1] no ano de 2015 foram extraídos 267,69 milhões de metros cúbicos de madeira e produzidos cerca de 1,93 milhões de toneladas de resíduos, que podem servir como combustível para produção de energia, mediante a liberação de $\mathrm{CO}_{2}$ ou, quando não tem uma destinação adequada, acabam sendo descartados em aterros, sofrendo processo de biodegradação e liberando metano, que chega a ser até 72 vezes pior que o $\mathrm{CO}_{2}$ para o efeito estufa [2].

Alguns resíduos de outras industrias também apresentam potencial de utilização, como a sílica ativa, que é um subproduto da fabricação do silício metálico e outras ligas de silício [3], e as cinzas de casca de arroz (CCA), que são um subproduto proveniente da queima da casca do arroz e que normalmente vem sendo descartado de forma inadequada no meio ambiente [4]. A vantagem do uso da CCA é que a fonte agrícola é farta. Dos 11,6 milhões de toneladas de arroz que o país produz por ano a casca corresponde a $20 \%$ desta massa (2,32 milhões de toneladas), que são rejeitadas, criando um grave problema ambiental, principalmente nas regiões onde o cultivo de arroz se faz em larga escala [5][6].

Outros resíduos que também apresentam potencial de utilização são os provenientes das indústrias siderúrgicas nacionais, como a escória de alto-forno (EAF), que é um subproduto da manufatura do ferro gusa, cuja produção foi de 7,69 milhões de toneladas em 2016 [7] e a as cinzas volantes (CV), que são resíduos oriundos da queima do carvão mineral para a produção de energia em centrais termelétricas, que se apresentam na forma de um pó nocivo ao meio ambiente. A produção mundial de CV é estimada em 500 milhões de toneladas por ano [8].

Há, ainda, o resíduo da produção da cerâmica vermelha, cuja produção se dá através da calcinação ou desidroxilação de argilas cauliníticas, líticas e montmoriloníticas em temperaturas entre $500^{\circ} \mathrm{C}$ e $800^{\circ} \mathrm{C}$, resultando em um material amorfo com propriedades pozolânicas,[9,10]. O resíduo de cerâmica calcinada (RCC) representa 5\% da produção nacional de cerâmica vermelha, ou 6,5 milhões de toneladas em 2016, ainda não utilizado como pozolana [11]. Outra fonte importante de RCC são os resíduos sólidos urbanos, pois conforme dados da ABRELPE [12], 63\% da massa dos resíduos sólidos urbanos têm origem no processo construtivo, dos quais $75,8 \%$ são dispostos em aterros sanitários ou lixões, sem qualquer critério de seleção. Em massa, o montante de resíduos de construção e demolição (RCD) gerados no Brasil no ano de 2016 foi de 45,1 milhões de toneladas. Como a participação de materiais cerâmicos atinge até 30\% do total de resíduos de construção e demolição, o montante de RCC resulta em mais de 13,3 milhões de toneladas/ano [13]. Somadas, estas duas fontes em potencial, tem capacidade de gerar até 19,8 milhões de toneladas/ano de RCC, que a princípio deixa de ter uma utilização economicamente viável e ambientalmente correta e segura.

Estes materiais, assim como o metacaulim (MK), oriundo da produção comercial de calcinação de argilas cauliníticas, são denominados pozolanas e possuem a capacidade de reagir com o $\mathrm{Ca}(\mathrm{OH})_{2}$ resultando na formação de compostos estáveis de poder aglomerante, podendo substituir, até certos teores, o cimento Portland [14]. 
As reações pozolânicas se processam quando a sílica existente nas pozolanas reage com o $\mathrm{Ca}(\mathrm{OH})_{2}$ resultante da hidratação do cimento Portland, formando os silicatos de cálcio hidratados, $\mathrm{CaO} \cdot \mathrm{SiO}_{2} \cdot \mathrm{H}_{2} \mathrm{O}$ ou C-S-H, que tem menor basicidade do que os produzidos pela hidratação dos silicatos de cálcio do cimento e são mais estáveis quimicamente. Esta reação, bem como a taxa de liberação de calor e o desenvolvimento da resistência são lentos e se dão conforme as expressões 1 e $2[15,16]$ :

$$
\begin{aligned}
& \text { Pozolana }+\mathrm{Ca}(\mathrm{OH})_{2}+\mathrm{H}_{2} \mathrm{O} \rightarrow \mathrm{CSH} \\
& 3 \mathrm{Ca}^{++}+2 \mathrm{H}_{2} \mathrm{SiO}_{4}{ }^{2-}+2 \mathrm{OH}^{-}+2 \mathrm{H}_{2} \mathrm{O} \rightarrow \mathrm{Ca}_{3}\left[\mathrm{H}_{2} \mathrm{Si}_{2} \mathrm{O}_{7}\right](\mathrm{OH})_{2} \cdot 3 \mathrm{H}_{2} \mathrm{O}
\end{aligned}
$$

Esta reação, por se dar a temperatura ambiente, é geralmente lenta e pode levar meses para ser completada, entretanto, quanto mais vítrea e mais fina for à pozolana, mais rápida será a reação com o $\mathrm{Ca}(\mathrm{OH})_{2}$ disponível.

O conceito de misturar fibras ou partículas vegetais, tais como partículas de madeira ou resíduos da produção agrícola em matrizes inorgânicas é muito antigo [17], pois desde os tempos pré-históricos já eram produzidos tijolos com misturas de argila e cascas de arroz ou trigo, que funcionavam como fibras de reforço, reduzindo o desenvolvimento de trincas e melhorando o desempenho do material produzido.

O interesse desta pesquisa está na busca de materiais de baixo custo, baixo consumo de energia, disponibilidade e ambientalmente seguros, pois além de resolver o problema da disposição dos resíduos gerados pela atividade industrial, visa, também, resguardar os recursos naturais e a redução das emissões de dióxido de carbono, quer pela queima da casca de arroz e do resíduo de Pinus spp. e pela produção do cimento Portland, que é reconhecida como altamente poluidora, responsável pela emissão de $971 \mathrm{~kg} \mathrm{CO}_{2}$ por tonelada de cimento produzido, o que corresponde a $5 \%$ das emissões de $\mathrm{CO}_{2}$ do planeta $[2,18,19]$.

Os compósitos cimento-madeira combinam partículas de madeira com aglomerante mineral, como o cimento Portland, o que confere uma série de vantagens, quando comparado a madeira ou ao cimentoamianto, tais como resistência ao fogo e as intempéries e bom isolamento acústico [20,21], estabilidade dimensional [22], resistência ao ataque de agentes biodegradadores [23[22] SOTANNDE, O.A., OLUWADARE, A.O., OGEDOH, O., et al., "Evaluation as cement-bonded particleboard produced from Afzelia Africana wood residues", Journal of Engineering Science and Technology, v. 7, n. 6, p. 732-743, 2012.

,24], elevada resistência em relação ao seu baixo peso [25], além de não emitir resíduos tóxicos durante a sua produção [26] e não utilizar amianto, já banido em diversos países e em alguns estados brasileiros [26,27].

Por outro lado, uma das principais desvantagens a ser citada, diz respeito à incompatibilidade química entre o cimento e a madeira. A constituição química da madeira, em função da presença de açúcares, resinas, fenóis e amido, podem afetar de forma adversa as reações de hidratação do cimento Portland [28].

Essa incompatibilidade, conforme diversos autores, pode ser reduzida mediante a utilização de prétratamentos que podem ser conferidos às partículas de madeira, como a remoção dos componentes inibidores da madeira através de técnicas de extração em água fria [29,30][29] LIMA, A.J.M., IWAKIRI, S., LOMELÍRAMIREZ, M.G. "Study of the interaction of Portland cement and Pinus wood for composites using Bragg sensors in optical fibers", BioResources, n.10, v. 4, p. 6690-6704, 2015.

- Outra formas de melhorar a compatibilidade entre o cimento Portland e a madeira é através da utilização de aditivos aceleradores da pega do cimento, como o cloreto de cálcio $[28,29,30]$.

$\mathrm{O} \mathrm{Ca}(\mathrm{OH})_{2}$ remanescente na matriz cimentícia hidratada aumenta o $\mathrm{pH}$ da pasta para aproximadamente 12,5 propiciando o inchamento, dissolução e degradação da madeira [21]. Esse aumento do $\mathrm{pH}$, segundo o autor, é capaz de remover grande parte dos extrativos e dissolver consideráveis partes dos componentes da madeira, especialmente a hemicelulose, proporcionando, também, alterações dimensionais no compósito cimento-madeira. Para reduzir a alcalinidade da matriz cimentícia, alguns autores recomendam a utilização de pozolanas [16,31].

A redução do $\mathrm{pH}$ nas matrizes cimentícias com substituição parcial do cimento por pozolanas pode ser explicado pela incorporação dos íons $\mathrm{OH}^{-}$e $\mathrm{Ca}^{2+}$ na estrutura do C-S-H formada durante as reações pozolânicas. A concentração dos íons presentes na solução dos poros de matrizes cimentícias é alterada com o tempo de hidratação do cimento. Após algumas horas da hidratação do cimento, a solução apresenta acréscimo das bases alcalinas, $\mathrm{KOH}$ e $\mathrm{NaOH}$, e um decréscimo da concentração de $\mathrm{Ca}(\mathrm{OH})_{2}$, que é menos solúvel. Com a adição das pozolanas, a alcalinidade da solução do poro é alterada de acordo com a composição química da adição utilizada [15]. 
O uso de pozolanas atrasa ou minimiza a degradação do material lignocelulósico em compósitos cimentícios, em função da redução do $\mathrm{pH}$ da matriz cimentícia e da remoção do excesso de $\mathrm{Ca}(\mathrm{OH})_{2}$ pela formação do C-S-H e pelo refinamento dos poros do compósito [32].

Buscando aprofundar o conhecimento sobre a influência das pozolanas sobre a alcalinidade de compósitos cimento madeira, neste trabalho, foram determinadas as variações do $\mathrm{pH}$ de compósitos produzidos com partículas residuais de Pinus spp. e com substituições parciais do cimento Portland por sílica ativa (SA), metacaulim (MK), cinza volante (CV), escória de alto-forno (EAF), cinza de casca de arroz (CCA) e resíduo de cerâmica calcinada $(\mathrm{RCC})$.

\section{MATERIAIS E MÉTODOS}

A pesquisa iniciou com a coleta e caracterização química e física do cimento Portland e das pozolanas. Da mesma forna, o resíduo de Pinus spp. foi coletado, peneirado e tratado para redução dos extrativos. Após este tratamento inicial, as parículas residuais de Pinus spp. também foram caraterizadas para determinação das suas características químicas e físicas. Em seguida foi realizado um planejamento experimental de forma a proporcionar uma ampla gama de misturas (compósitos), em função da variação dos teores de cimento, das pozolanas e dos aditivos químicos utilizados. O teor de resíduo de Pinus spp. e a relação água/cimento das misturas foram mantidos constantes em todas as misturas e seguiram valores ideais determinados pelos autores [29]. Os compósitos foram, então, produzidos e permeceram em cura por 91 dias, após este período foram triturados e caracterizados quanto a variação do $\mathrm{pH}$.

As partículas residuais de Pinus spp. são provenientes de uma madeireira situada no município de Almirante Tamandaré (PR). A sílica ativa (SA), de nome comercial Silmix ${ }^{\circledR}$ e o metacaulim (MK), de nome comercial Metacaulim HP®, foram adquiridos em loja de materiais de construção na cidade de Curitiba (PR), a cinza volante (CV) utilizada é oriunda da Usina Termelétrica de Charqueadas, município de Charqueadas (RS), a escória de alto-forno (EAF) é oriunda da Companhia Siderúrgica Paulista - COSIPA, Cubatão (SP), a cinza de casca de arroz (CCA) é oriunda da cidade de Jaraguá (SC) e o resíduo de cerâmica calcinada (RCC), fornecido por uma olaria localizada no município de Curitiba (PR).

O cimento Portland utilizado nesta pesquisa foi o CPV- ARI, adquirido no mercado de Curitiba (PR). Foram, também utilizados, o aditivo químico acelerador de pega, cloreto de cálcio bi-hidratado $\left(\mathrm{CaCl}_{2} \cdot 2 \mathrm{H}_{2} \mathrm{O}\right)$, com $\mathrm{pH}=8,50$, produzido pela IPC do Nordeste Ltda., produzido em Camaçari (BA) e o aditivo superplastificante de primeira geração Muraplast FK 49B, fabricado e distribuído pela MC Bauchemie Brasil Indústria e Comércio Ltda. e com $\mathrm{pH}=8,76$. As características químicas e físicas do cimento e das pozolanas, obtidas por fluorescência e difratometria de raios-x, são apresentadas na Tabela 1. As características do resíduo de Pinus spp. são apresentadas na Tabela 2.

Tabela 1: Características químicas e físicas do cimento Portland e das pozolanas utilizadas.

\begin{tabular}{|c|c|c|c|c|c|c|c|c|}
\hline \multicolumn{2}{|c|}{ CARACTERÍSTICAS } & CIMENTO & SA & MK & CV & EAF & CCA & RCC \\
\hline $\mathrm{iO}_{2}$ & $\%$ & 18,86 & 95,80 & 59,05 & 37,40 & 59,05 & 70,56 & 58,26 \\
\hline $\mathrm{Al}_{2} \mathrm{O}_{3}$ & $\%$ & 4,19 & 0,07 & 25,98 & 12,94 & 25,98 & 0,17 & 25,24 \\
\hline $\mathrm{Fe}_{2} \mathrm{O}_{3}$ & $\%$ & 2,56 & 0,06 & 5,21 & 0,72 & 5,21 & 0,15 & 7,49 \\
\hline $\mathrm{CaO}$ & $\%$ & 60,51 & 0,23 & 0,40 & 39,57 & 0,40 & 0,20 & 0,18 \\
\hline $\mathrm{MgO}$ & $\%$ & 4,21 & 0,48 & 0,47 & 4,79 & 0,47 & 0,03 & 0,17 \\
\hline $\mathrm{K}_{2} \mathrm{O}$ & $\%$ & - & 0,67 & 2,79 & 0,54 & 2,79 & 0,03 & 0,29 \\
\hline $\mathrm{NaO}_{2}$ & $\%$ & - & 0,18 & 0,07 & 0,25 & 0,07 & - & - \\
\hline $\mathrm{TiO}_{2}$ & $\%$ & - & - & - & 0,73 & - & - & 0,90 \\
\hline $\mathrm{SO}_{3}$ & $\%$ & 2,96 & - & - & 1,92 & - & 0,40 & 0,05 \\
\hline $\begin{array}{l}\text { Perda ao } \\
\text { Fogo }\end{array}$ & $\%$ & 3,44 & - & 5,41 & - & 5,41 & - & - \\
\hline $\mathrm{H}_{2} \mathrm{O}$ & $\%$ & - & 0,29 & - & - & - & - & - \\
\hline $\mathrm{CO}_{2}$ & $\%$ & - & - & 28,70 & - & 28,70 & - & 7,26 \\
\hline $\mathrm{pH}$ & & 12,73 & 8,82 & 8,85 & 11,98 & 8,85 & 6,00 & 6,10 \\
\hline $\begin{array}{l}\text { Finura \# } \\
325\end{array}$ & $\%$ & 0,48 & 1,10 & 46,80 & 7,80 & 46,80 & 0,85 & 0,73 \\
\hline Sup. Esp. & $\mathrm{cm}^{2} / \mathrm{g}$ & $4.292,00$ & $220.000,00$ & $2.710,00$ & $6.800,00$ & $2.710,00$ & $14.780,00$ & $14.950,00$ \\
\hline
\end{tabular}




\begin{tabular}{l|l|l|l|l|l|l|l|l}
$\begin{array}{l}\text { Massa } \\
\text { Esp. }\end{array}$ & $\mathrm{g} / \mathrm{cm}^{3}$ & 3,09 & 2,19 & 2,06 & 2,92 & 2,06 & 2,02 & 2,61 \\
\hline
\end{tabular}

AS: Sílica ativa; MK: Metacaulim; CV: Cinza volante; EAF: Escória de alto-forno; CCA: Cinza de casca de arroz; RCC:

Resíduo de cerâmica calcinada.

Tabela 2: Características químicas e físicas do resíduo de Pinus spp.

\begin{tabular}{lc|c|c}
\hline \multicolumn{1}{c|}{ CARACTERÍSTICAS } & & MÉTODO & RESULTADO \\
\hline Massa Específica U $=0 \%$ & $\left(\mathrm{~g} / \mathrm{cm}^{3}\right)$ & ABNT NBR NM 52: 2009 [33] & 1,28 \\
Massa Unitária (Madeira Particulada) U $=0 \%$ & $\left(\mathrm{~g} / \mathrm{cm}^{3}\right)$ & ABNT NBR NM 52: 2009 [33] & 0,17 \\
Massa Unitária (Madeira Sólida) U =0\% & $\left(\mathrm{g} / \mathrm{cm}^{3}\right)$ & ABNT NBR 7190: 1997 [34] & 0,41 \\
Dimensão Máxima Característica & $(\mathrm{mm})$ & ABNT NBR NM 248: 2003[35] & 2,40 \\
Absorção de Água & $(\%)$ & ABNT NBR 7190: 1997 [34] & 129,62 \\
\hline Extrativos Totais & $(\%)$ & TAPPI T 204 CM: 2017 [36] & 2,43 \\
pH & & TAPPI T 252 OM: 2016 [37] & 5,07 \\
\hline
\end{tabular}

Nesta pesquisa foram analisadas a alcalinidade de compósitos cimento-madeira em função da substituição parcial do cimento Portland pelas pozolanas: SA, MK, CV, EAF, CCA e RCC. Para cada análise foi planejado um experimento fatorial tipo $2^{\mathrm{k}}$, onde dois fatores seriam analisados (teor de substituição e teor de aditivo acelerador de pega), cada um em cinco níveis, ou seja, foram testados os teores de $0 \%, 5 \%, 10 \%$, $15 \%$ e $20 \%$ de substituição do cimento por SA, substituições do cimento por $0 \%, 10 \%, 20 \%, 30 \%$ e $40 \%$ de MK, CV, CCA e RCC, e substituições do cimento por $0 \%, 30 \%, 40 \%, 50 \%$ e $60 \%$ de EAF, e em todas as composições, seriam utilizados os teores de $0 \%, 1 \%, 2 \%, 3 \%$ e 4,5\% de $\mathrm{CaCl}_{2} \cdot 2 \mathrm{H}_{2} \mathrm{O}$. Para cada determinação seriam testados três exemplares.

Desta forma o planejamento fatorial completo resultaria em uma grande quantidade de combinações. Optou-se, então, por um planejamento fatorial fracionário, tipo $2^{\mathrm{k}-\mathrm{p}}$, com um arranjo experimental para análise de superfície de resposta do tipo arranjo central composto de Box-Wilson [38]. O delineamento experimental foi obtido testando a composição central da matriz $5 \times 5$, quatro posições que circundam a posição central e mais quatro posições em uma área mais externa ao núcleo da matriz (forma de estrela). As composições resultantes são apresentadas na Tabelas 3, 4 e 5.

Tabela 3: Planejamento experimental para análise da alcalinidade do compósito em função da substituição do cimento por SA.

\begin{tabular}{c|c|c|c|cc}
\hline TRATAMENTO & $\begin{array}{c}\text { CIMENTO } \\
(\boldsymbol{\%})\end{array}$ & $\begin{array}{c}\text { SA } \\
(\boldsymbol{\%})\end{array}$ & $\begin{array}{c}\mathbf{C a C l}_{\mathbf{2}} \mathbf{2 H} \mathbf{O} \\
\mathbf{( \% )}\end{array}$ & $\begin{array}{c}\text { SP } \\
(\boldsymbol{\%})\end{array}$ \\
\hline 1 & $100 \%$ & - & - & - \\
2 & $100 \%$ & - & $4,5 \%$ & - \\
3 & $95 \%$ & $5 \%$ & $2,0 \%$ & $0,3 \%$ \\
4 & $90 \%$ & $10 \%$ & $1,0 \%$ & $0,8 \%$ \\
5 & $90 \%$ & $10 \%$ & $2,0 \%$ & $1,0 \%$ \\
6 & $90 \%$ & $10 \%$ & $3,0 \%$ & $1,2 \%$ \\
7 & $85 \%$ & $15 \%$ & $2,0 \%$ & $2,0 \%$ \\
9 & $80 \%$ & $20 \%$ & - & $3,0 \%$ \\
\hline
\end{tabular}

Tabela 4: Planejamento experimental para análise da alcalinidade do compósito em função da substituição do cimento por MK, CV, CCA e RCC.

\begin{tabular}{c|c|c|c|c}
\hline TRATAMENTO & $\begin{array}{c}\text { CIMENTO } \\
(\boldsymbol{\%})\end{array}$ & $\begin{array}{c}\text { MK, CV, } \\
\text { CCA e RCC } \\
(\boldsymbol{\%})\end{array}$ & $\begin{array}{c}\mathbf{C a C l}_{\mathbf{2}} \mathbf{2 H} \mathbf{O} \mathbf{O} \\
(\mathbf{\%})\end{array}$ & $\begin{array}{c}\text { SP } \\
(\boldsymbol{\%})\end{array}$ \\
\hline 1 & $100 \%$ & - & - & - \\
2 & $100 \%$ & - & $4,5 \%$ & - \\
3 & $90 \%$ & $10 \%$ & $2,0 \%$ & $1,4 \%$ \\
4 & $80 \%$ & $20 \%$ & $1,0 \%$ & $2,4 \%$ \\
5 & $80 \%$ & $20 \%$ & $2,0 \%$ & $2,4 \%$ \\
6 & $80 \%$ & $20 \%$ & $3,0 \%$ & $2,4 \%$
\end{tabular}




\begin{tabular}{c|c|c|c|c}
7 & $70 \%$ & $30 \%$ & $2,0 \%$ & $3,0 \%$ \\
8 & $60 \%$ & $40 \%$ & - & $3,4 \%$ \\
9 & $60 \%$ & $40 \%$ & $4,5 \%$ & $4,2 \%$ \\
\hline
\end{tabular}

Tabela 5: Planejamento experimental para análise da alcalinidade do compósito em função da substituição do cimento por escória de alto-forno (EAF).

\begin{tabular}{c|c|c|c|cc}
\hline TRATAMENTO & $\begin{array}{c}\text { CIMENTO } \\
(\boldsymbol{\%})\end{array}$ & $\begin{array}{c}\text { EAF } \\
(\boldsymbol{\%})\end{array}$ & $\begin{array}{c}\mathbf{C a C l}_{\mathbf{2}} \mathbf{2} \mathbf{H}_{\mathbf{2}} \mathbf{O} \\
(\boldsymbol{\%})\end{array}$ & $\begin{array}{c}\text { SP } \\
(\boldsymbol{\%})\end{array}$ \\
\hline 1 & $100 \%$ & - & - & - \\
2 & $100 \%$ & - & $4,5 \%$ & - \\
3 & $70 \%$ & $30 \%$ & $2,0 \%$ & - & - \\
4 & $60 \%$ & $40 \%$ & $1,0 \%$ & - & - \\
5 & $60 \%$ & $40 \%$ & $2,0 \%$ & - \\
6 & $60 \%$ & $40 \%$ & $3,0 \%$ & - \\
7 & $50 \%$ & $50 \%$ & $2,0 \%$ & - & - \\
\hline
\end{tabular}

Os compósitos foram produzidos com $200 \mathrm{~g}$ de cimento Portland para $15 \mathrm{~g}$ de partículas de Pinus spp. absolutamente secas, assegurando uma relação madeira/cimento de 1:13,33 e a relação água/cimento de 0,40 . Essa composição, apresentada em [39], clássica no estudo de compósitos cimento-madeira, foi escolhida para evidenciar o efeito da substituição sobre a alcalinidade do compósito. A confecção dos corpos de prova cilíndricos, com diâmetro de $50 \mathrm{~mm}$, seguiu os procedimentos descritos na norma ABNT NBR 7215: 2009 [40]. Para correção do teor de água, foi considerado o ponto de saturação das fibras da madeira (PSF) de $30 \%$. O teor de aditivo superplastificante variou em função do teor e tipo de pozolana utilizada.

Os compósitos foram preparados em um misturador mecânico Emic AG-5 (Instron Brasil) equipado com uma cuba de aço inox de capacidade para 5 litros, A mistura dos materiais foi feita em velocidades de $140 \pm 5 \mathrm{rpm}$ e $285 \pm 5 \mathrm{rpm}$, de acordo com a norma ABNT NBR 7215: 2009 [40]. Depois de preparados foi determinada a consistência do compósito no estado fresco, em mesa cadente, também de acordo com a NBR 7215 [40]. A consistência determinada para o compósito de referência sem substituição do cimento Portland, igual a $250 \pm 5 \mathrm{~mm}$, foi adotada como padrão para os demais compósitos, balizando a necessidade de adição do aditivo superplastificante, que variou entre $0 \%$ a $4,4 \%$ para substituição por SA, $0 \%$ a $7,8 \%$ para substituição por MK, $0 \%$ a $4,2 \%$ para substituições por CCA e $0 \%$ a 2,6\% para substituições por RCC. Nas substituições do cimento por $\mathrm{CV}$ e EAF, não foi necessário utilizar aditivo superplastificante, devido ao efeito microfiller apresentado por estas pozolanas.

A cura inicial com duração de 24 horas deu-se em câmara úmida, em temperatura de $23 \pm 2^{\circ} \mathrm{C}$ e UR $\geq$ $95 \%$. Após a cura inicial, os corpos de prova foram desmoldados e mantidos em câmara úmida para cura final, onde permaneceram imersos em água para evitar a carbonatação, até a data de ensaio, ou seja, por mais 90 dias.

Após a cura final, os compósitos foram moídos em moinho de panelas e o material peneirado em peneira de abertura $0,15 \mathrm{~mm}$ (100 mesh) e acondicionados em frascos com água deionizada, numa relação L:S igual a 10:1. O material foi agitado e deixado em repouso por 36 horas. Após este período foram feitas as leituras do $\mathrm{pH}$ da solução de equilíbrio, mediante o uso de peagâmetro digital PHTEK, modelo PHS-3E, com compensação automática de temperatura. Os resultados foram analisados estatisticamente através de ANOVA e as médias dos valores encontrados foram comparadas através do teste de Tukey, a um nível de confiança de $95 \%$.

\section{RESULTADOS}

Os valores do pH das soluções de equilíbrio, após 91 dias de cura dos compósitos, apresentaram os resultados contidos nas Tabelas 6 a 11 .

Tabela 6: Variação do pH do compósito em função da substituição parcial do cimento por AS.

\begin{tabular}{l|l|l|l|l|l|l|l|}
\hline TRATAMENTO & SA & $\mathrm{CaCl}_{2 .} 2 \mathrm{H}_{2} \mathrm{O}$ & SP & pH & cv & EP & VAR \\
\hline
\end{tabular}




\begin{tabular}{c|c|c|c|c|c|cc|c}
\hline & $\mathbf{( \% )}$ & $\mathbf{( \% )}$ & $\mathbf{( \% )}$ & & $\mathbf{( \% )}$ & & $\mathbf{( \% )}$ \\
\hline 1 & - & - & - & $12,67 \mathrm{~A}$ & 0,09 & 0,007 & - \\
2 & - & $4,5 \%$ & - & $12,60 \mathrm{~B}$ & 0,05 & 0,003 & $-0,55$ \\
3 & $5 \%$ & $2,0 \%$ & $0,3 \%$ & $12,31 \mathrm{C}$ & 0,09 & 0,007 & $-2,84$ \\
4 & $10 \%$ & $1,0 \%$ & $0,8 \%$ & $12,30 \mathrm{C}$ & 0,05 & 0,003 & $-2,92$ \\
5 & $10 \%$ & $2,0 \%$ & $1,0 \%$ & $12,24 \mathrm{D}$ & 0,09 & 0,007 & $-3,39$ \\
6 & $10 \%$ & $3,0 \%$ & $1,2 \%$ & $12,20 \mathrm{E}$ & 0,05 & 0,003 & $-3,71$ \\
7 & $15 \%$ & $2,0 \%$ & $2,0 \%$ & $12,14 \mathrm{~F}$ & 0,14 & 0,010 & $-4,18$ \\
8 & $20 \%$ & - & $3,0 \%$ & $12,07 \mathrm{G}$ & 0,25 & 0,017 & $-4,74$ \\
9 & $20 \%$ & $4,5 \%$ & $4,4 \%$ & $11,40 \mathrm{H}$ & 0,05 & 0,003 & $-10,02$ \\
\hline
\end{tabular}

Letras diferentes na coluna do $\mathrm{pH}$ indicam diferenças estatísticas entre as médias ao nível de confiança de 95\%; Médias obtidas através de 3 repetições; SA: Sílica ativa; SP: Aditivo superplastificante; cv: Coeficiente de variação; EP: Erro padrão; VAR: Variação percentual.

Tabela 7: Variação do pH do compósito em função da substituição parcial do cimento por MK.

\begin{tabular}{c|c|c|c|c|c|c|c}
\hline TRATAMENTO & $\begin{array}{c}\mathbf{M K} \\
(\mathbf{\%})\end{array}$ & $\begin{array}{c}\mathbf{C a C l}_{\mathbf{2}} \mathbf{2} \mathbf{H}_{\mathbf{2}} \mathbf{O} \\
(\mathbf{\%})\end{array}$ & $\begin{array}{c}\mathbf{S P} \\
\mathbf{( \% )}\end{array}$ & $\mathbf{p H}$ & $\begin{array}{c}\mathbf{c v} \\
\mathbf{( \% )}\end{array}$ & $\mathbf{E P}$ & $\begin{array}{c}\text { VAR } \\
(\boldsymbol{\%})\end{array}$ \\
\hline 1 & - & - & - & $12,67 \mathrm{~A}$ & 0,09 & 0,007 & - \\
2 & - & $4,5 \%$ & - & $12,60 \mathrm{~B}$ & 0,05 & 0,003 & $-0,55$ \\
3 & $10 \%$ & $2,0 \%$ & $0,7 \%$ & $12,33 \mathrm{D}$ & 0,09 & 0,007 & $-2,68$ \\
4 & $20 \%$ & $1,0 \%$ & $2,6 \%$ & $12,38 \mathrm{C}$ & 0,19 & 0,013 & $-2,29$ \\
5 & $20 \%$ & $2,0 \%$ & $2,6 \%$ & $12,26 \mathrm{E}$ & 0,12 & 0,009 & $-3,24$ \\
6 & $20 \%$ & $3,0 \%$ & $2,8 \%$ & $12,22 \mathrm{~F}$ & 0,05 & 0,003 & $-3,55$ \\
7 & $30 \%$ & $2,0 \%$ & $4,6 \%$ & $11,58 \mathrm{G}$ & 0,33 & 0,022 & $-8,60$ \\
8 & $40 \%$ & - & $5,8 \%$ & $11,41 \mathrm{H}$ & 0,13 & 0,009 & $-9,94$ \\
9 & $40 \%$ & $4,5 \%$ & $7,8 \%$ & $11,08 \mathrm{I}$ & 0,05 & 0,003 & $-12,55$ \\
\hline
\end{tabular}

Letras diferentes na coluna do $\mathrm{pH}$ indicam diferenças estatísticas entre as médias ao nível de confiança de 95\%; Médias obtidas através de 3 repetições; MK: Metacaulim; SP: Aditivo superplastificante; cv: Coeficiente de variação; EP: Erro padrão; VAR: Variação percentual.

Tabela 8: Variação do pH do compósito em função da substituição parcial do cimento por CV.

\begin{tabular}{c|c|c|c|c|c|c|c}
\hline TRATAMENTO & $\begin{array}{c}\mathbf{C V} \\
(\boldsymbol{\%})\end{array}$ & $\begin{array}{c}\mathbf{C a C l}_{\mathbf{2}} \mathbf{2} \mathbf{H}_{\mathbf{2}} \mathbf{O} \\
\mathbf{( \% )}\end{array}$ & $\begin{array}{c}\mathbf{S P} \\
(\boldsymbol{\%})\end{array}$ & $\mathbf{p H}$ & $\begin{array}{c}\mathbf{c V} \\
(\boldsymbol{\%})\end{array}$ & $\mathbf{E P}$ & $\begin{array}{c}\text { VAR } \\
(\boldsymbol{\%})\end{array}$ \\
\hline 1 & - & - & - & $12,67 \mathrm{~A}$ & 0,09 & 0,007 & - \\
2 & - & $4,5 \%$ & - & $12,60 \mathrm{~B}$ & 0,05 & 0,003 & $-0,55$ \\
3 & $10 \%$ & $2,0 \%$ & - & $12,36 \mathrm{C}$ & 0,08 & 0,006 & $-2,45$ \\
4 & $20 \%$ & $1,0 \%$ & - & $12,36 \mathrm{CD}$ & 0,12 & 0,009 & $-2,54$ \\
5 & $20 \%$ & $2,0 \%$ & - & $12,33 \mathrm{D}$ & 0,05 & 0,003 & $-2,68$ \\
6 & $20 \%$ & $3,0 \%$ & - & $12,31 \mathrm{E}$ & 0,05 & 0,003 & $-2,84$ \\
7 & $30 \%$ & $2,0 \%$ & - & $12,24 \mathrm{~F}$ & 0,05 & 0,003 & $-3,39$ \\
8 & $40 \%$ & - & - & $12,25 \mathrm{~F}$ & 0,25 & 0,018 & $-3,31$ \\
9 & $40 \%$ & $4,5 \%$ & - & $12,02 \mathrm{G}$ & 0,17 & 0,012 & $-5,13$ \\
\hline
\end{tabular}

Letras diferentes na coluna do $\mathrm{pH}$ indicam diferenças estatísticas entre as médias ao nível de confiança de 95\%; Médias obtidas através de 3 repetições; CV: Cinza volante; cv: Coeficiente de variação; EP: Erro padrão; VAR: Variação percentual.

Tabela 9: Variação do pH do compósito em função da substituição parcial do cimento por EAF.

\begin{tabular}{c|c|c|c|c|c|c|c}
\hline TRATAMENTO & $\begin{array}{c}\text { EAF } \\
(\boldsymbol{\%})\end{array}$ & $\begin{array}{c}\mathbf{C a C l}_{\mathbf{2}} \mathbf{2} \mathbf{H}_{\mathbf{2}} \mathbf{O} \\
(\mathbf{\%})\end{array}$ & $\begin{array}{c}\mathbf{S P} \\
(\boldsymbol{\%})\end{array}$ & $\mathbf{p H}$ & $\begin{array}{c}\mathbf{c v} \\
(\boldsymbol{\%})\end{array}$ & $\mathbf{E P}$ & $\begin{array}{c}\text { VAR } \\
(\boldsymbol{\%})\end{array}$ \\
\hline 1 & - & - & - & $12,67 \mathrm{~A}$ & 0,09 & 0,007 & - \\
2 & - & $4,5 \%$ & - & $12,60 \mathrm{~B}$ & 0,05 & 0,003 & $-0,55$ \\
3 & $30 \%$ & $2,0 \%$ & - & $12,37 \mathrm{E}$ & 0,17 & 0,012 & $-2,37$ \\
4 & $40 \%$ & $1,0 \%$ & - & $12,47 \mathrm{C}$ & 0,08 & 0,006 & $-1,58$ \\
5 & $40 \%$ & $2,0 \%$ & - & $12,40 \mathrm{D}$ & 0,05 & 0,003 & $-2,31$ \\
6 & $40 \%$ & $3,0 \%$ & - & $12,34 \mathrm{~F}$ & 0,05 & 0,003 & $-2,60$ \\
7 & $50 \%$ & $2,0 \%$ & - & $12,28 \mathrm{G}$ & 0,08 & 0,006 & $-3,08$ \\
8 & $60 \%$ & - & - & $12,35 \mathrm{~F}$ & 0,08 & 0,006 & $-2,53$ \\
9 & $60 \%$ & $4,5 \%$ & - & $12,18 \mathrm{H}$ & 0,17 & 0,012 & $-3,87$ \\
\hline
\end{tabular}


Letras diferentes na coluna do $\mathrm{pH}$ indicam diferenças estatísticas entre as médias ao nível de confiança de 95\%; Médias obtidas através de 3 repetições; EAF: Escória de alto-forno; cv: Coeficiente de variação; EP: Erro padrão; VAR: Variação percentual.

Tabela 10: Variação do pH do compósito em função da substituição parcial do cimento por CCA.

\begin{tabular}{c|c|c|c|c|c|c|c}
\hline TRATAMENTO & $\begin{array}{c}\mathbf{C C A} \\
(\boldsymbol{\%})\end{array}$ & $\begin{array}{c}\mathbf{C a C l}_{\mathbf{2}} \mathbf{2} \mathbf{H}_{\mathbf{2}} \mathbf{O} \\
\mathbf{( \% )}\end{array}$ & $\begin{array}{c}\mathbf{S P} \\
\mathbf{( \% )}\end{array}$ & $\mathbf{p H}$ & $\begin{array}{c}\mathbf{c v} \\
(\boldsymbol{\%})\end{array}$ & $\mathbf{E P}$ & $\begin{array}{c}\text { VAR } \\
(\boldsymbol{\%})\end{array}$ \\
\hline 1 & - & - & - & $12,67 \mathrm{~A}$ & 0,09 & 0,007 & - \\
2 & - & $4,5 \%$ & - & $12,60 \mathrm{~B}$ & 0,05 & 0,003 & $-0,55$ \\
3 & $10 \%$ & $2,0 \%$ & $1,4 \%$ & $12,29 \mathrm{C}$ & 0,05 & 0,003 & $-3,00$ \\
4 & $20 \%$ & $1,0 \%$ & $2,4 \%$ & $12,25 \mathrm{D}$ & 0,08 & 0,006 & $-3,31$ \\
5 & $20 \%$ & $2,0 \%$ & $2,4 \%$ & $12,11 \mathrm{E}$ & 0,13 & 0,009 & $-4,42$ \\
6 & $20 \%$ & $3,0 \%$ & $2,4 \%$ & $11,75 \mathrm{~F}$ & 0,05 & 0,003 & $-7,26$ \\
7 & $30 \%$ & $2,0 \%$ & $3,0 \%$ & $11,65 \mathrm{G}$ & 0,36 & 0,024 & $-8,05$ \\
8 & $40 \%$ & - & $3,4 \%$ & $11,38 \mathrm{H}$ & 0,33 & 0,022 & $-10,18$ \\
9 & $40 \%$ & $4,5 \%$ & $4,2 \%$ & $10,75 \mathrm{I}$ & 0,14 & 0,009 & $-15,15$ \\
\hline
\end{tabular}

Letras diferentes na coluna do $\mathrm{pH}$ indicam diferenças estatísticas entre as médias ao nível de confiança de 95\%; Médias obtidas através de 3 repetições; CCA: Cinza de casca de arroz; SP: Aditivo superplastificante; cv: Coeficiente de variação; EP: Erro padrão; VAR: Variação percentual.

Tabela 11: Variação do pH do compósito em função da substituição parcial do cimento por RCC.

\begin{tabular}{c|c|c|c|c|c|c|c}
\hline TRATAMENTO & $\begin{array}{c}\mathbf{R C C} \\
(\mathbf{\%})\end{array}$ & $\begin{array}{c}\mathbf{C a C l}_{\mathbf{2}} \mathbf{2} \mathbf{H}_{\mathbf{2}} \mathbf{O} \\
\mathbf{( \% )}\end{array}$ & $\begin{array}{c}\mathbf{S P} \\
\mathbf{( \% )}\end{array}$ & $\mathbf{p H}$ & $\begin{array}{c}\mathbf{c v} \\
\mathbf{( \% )}\end{array}$ & $\mathbf{E P}$ & $\begin{array}{c}\text { VAR } \\
(\boldsymbol{\%})\end{array}$ \\
\hline 1 & - & - & - & $12,67 \mathrm{~A}$ & 0,09 & 0,007 & - \\
2 & - & $4,5 \%$ & - & $12,60 \mathrm{~B}$ & 0,05 & 0,003 & $-0,55$ \\
3 & $10 \%$ & $2,0 \%$ & $0,5 \%$ & $12,30 \mathrm{CD}$ & 0,05 & 0,003 & $-2,92$ \\
4 & $20 \%$ & $1,0 \%$ & $0,6 \%$ & $12,33 \mathrm{C}$ & 0,09 & 0,007 & $-2,68$ \\
5 & $20 \%$ & $2,0 \%$ & $0,6 \%$ & $12,30 \mathrm{CD}$ & 0,05 & 0,003 & $-2,92$ \\
6 & $20 \%$ & $3,0 \%$ & $0,6 \%$ & $12,27 \mathrm{D}$ & 0,05 & 0,003 & $-3,16$ \\
7 & $30 \%$ & $2,0 \%$ & $1,2 \%$ & $12,27 \mathrm{D}$ & 0,14 & 0,010 & $-3,16$ \\
8 & $40 \%$ & - & $2,6 \%$ & $11,93 \mathrm{E}$ & 0,59 & 0,040 & $-5,84$ \\
9 & $40 \%$ & $4,5 \%$ & $2,6 \%$ & $11,62 \mathrm{~F}$ & 0,13 & 0,009 & $-8,29$ \\
\hline
\end{tabular}

Letras diferentes na coluna do $\mathrm{pH}$ indicam diferenças estatísticas entre as médias ao nível de confiança de 95\%; Médias obtidas através de 3 repetições; RCC: Resíduo de cerâmica calcinada; SP: Aditivo superplastificante; cv: Coeficiente de variação; EP: Erro padrão; VAR: Variação percentual.

Para caracterização de uma função que expresse a variação do pH do compósito em função dos teores de substituição do cimento Portland pelas pozolanas utilizadas, procedeu-se uma análise multivariada mediante regressão múltipla, onde o pH dos compósitos é a variável dependente e o teor de substituição do cimento e o teor de $\mathrm{CaCl}_{2} \cdot 2 \mathrm{H}_{2} \mathrm{O}$, são as variáveis independentes. Para simplificar essa análise assumiu-se que o aditivo superplastificante, utilizado em pequenas quantidades e apenas para manter a consistência do compósito, figura como uma variável espúria ou de controle. Tais relações podem embasar futuras pesquisas, de modo a permitir uma previsão da alcalinidade dos compósitos produzidos com substituições do cimento pelas pozzolanas estudadas. Tais funções são apresentadas na Tabela 12.

Tabela 12: Funções que representam a variação do $\mathrm{pH}$ do compósito em função da substituição parcial do cimento pelas pozolanas e do teor de $\mathrm{CaCl}_{2}$.

\begin{tabular}{c|c|c|c|c}
\hline POZOLANA & FUNÇÃO & R & $\mathbf{R}^{2}$ & SIGNIFICÂNCIA \\
\hline SA & $\mathrm{pH}=12,802-0,04178 .(\mathrm{SA})-0,08043 .\left(\mathrm{CaCl}_{2}\right)$ & 0,9374 & 0,8777 & $10,0.10^{-9} \%$ \\
\hline MK & $\mathrm{pH}=12,871-0,03498 .(\mathrm{MK})-0,05327 .\left(\mathrm{CaCl}_{2}\right)$ & 0,9514 & 0,9052 & $5,3.10^{-11} \%$ \\
\hline $\mathrm{CV}$ & $\mathrm{pH}=12,649-0,01796 .(\mathrm{CV})-0,03074 .\left(\mathrm{CaCl}_{2}\right)$ & 0,9528 & 0,9078 & $3,8.10^{-11} \%$ \\
\hline EAF & $\mathrm{pH}=12,693-0,0062413 .(\mathrm{EAF})-0,03073 .\left(\mathrm{CaCl}_{2}\right)$ & 0,9608 & 0,9231 & $4,3 \cdot 10^{-12} \%$ \\
\hline
\end{tabular}




\begin{tabular}{c|l|l|l|c}
\hline CCA & $\mathrm{pH}=12,911-0,03837 .(\mathrm{CCA})-0,0971 .\left(\mathrm{CaCl}_{2}\right)$ & 0,9678 & 0,9367 & $4,2 \cdot 10^{-13} \%$ \\
\hline RCC & $\mathrm{pH}=12,731-0,019222 .(\mathrm{RCC})-0,054339 .\left(\mathrm{CaCl}_{2}\right)$ & 0,9342 & 0,8727 & $1,8 \cdot 10^{-9} \%$ \\
\hline
\end{tabular}

SA: Sílica ativa; MK: Metacaulim; CV: Cinza volante; EAF: Escória de alto-forno; CCA: Cinza de casca de arroz; RCC: Resíduo de cerâmica calcinada; R: Coeficiente de Correlação; $\mathrm{R}^{2}$ : Coeficiente de determinação.

Na Figura 1 são apresentados as superfícies de resposta que demonstram a variação do $\mathrm{pH}$ dos compósitos em função das substituições do cimento Portland dos compósitos cimento-madeira Pinus spp.

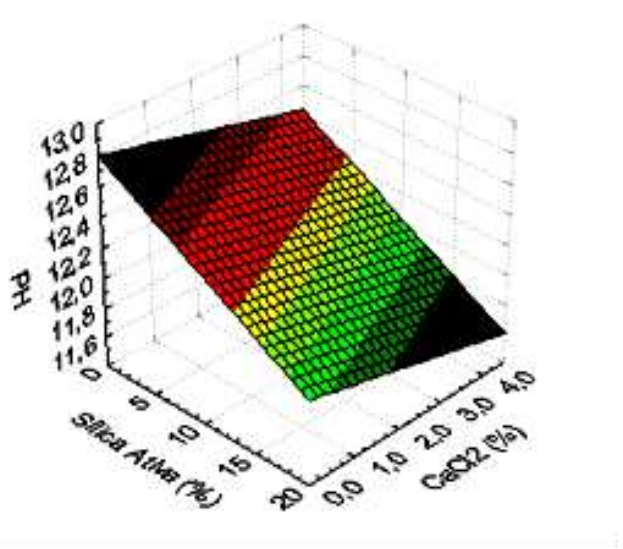

(a)

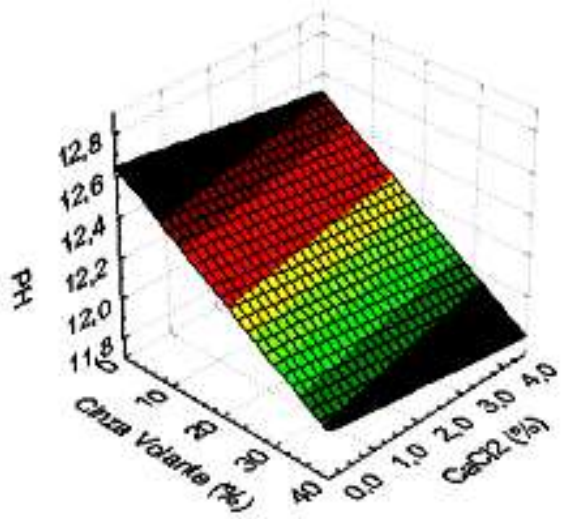

(c)

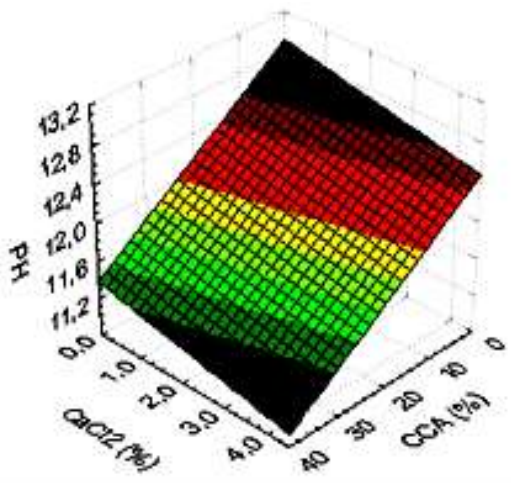

(e)
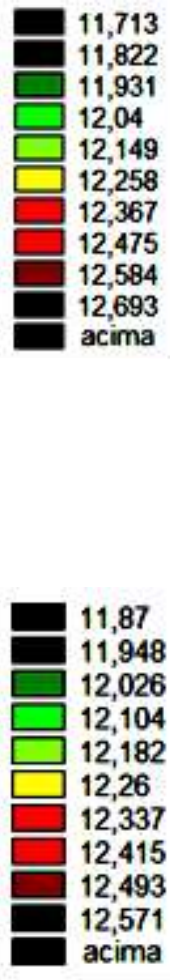

足

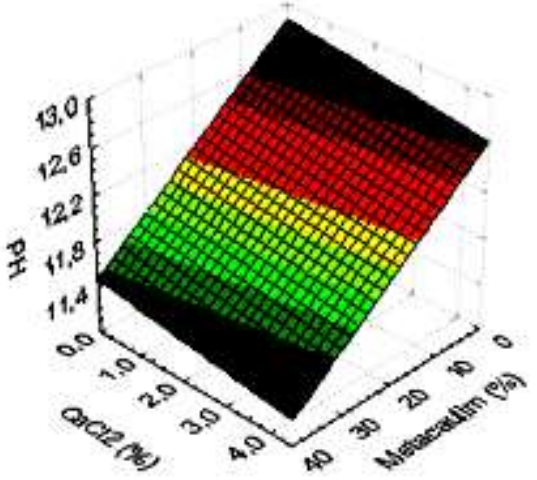

(b)

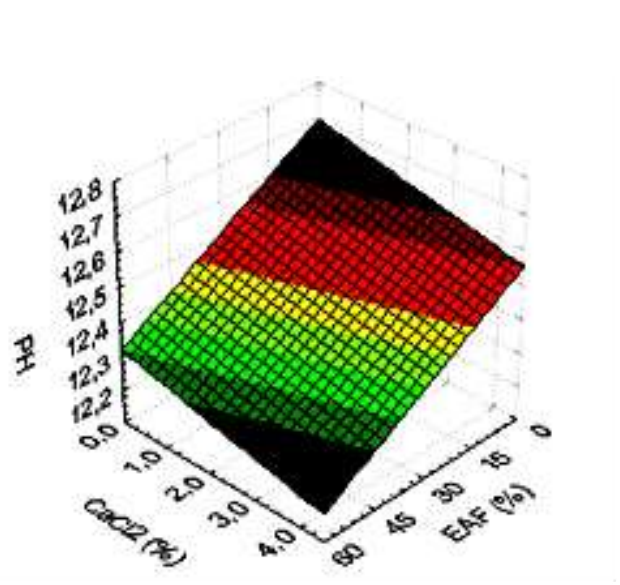

(d)
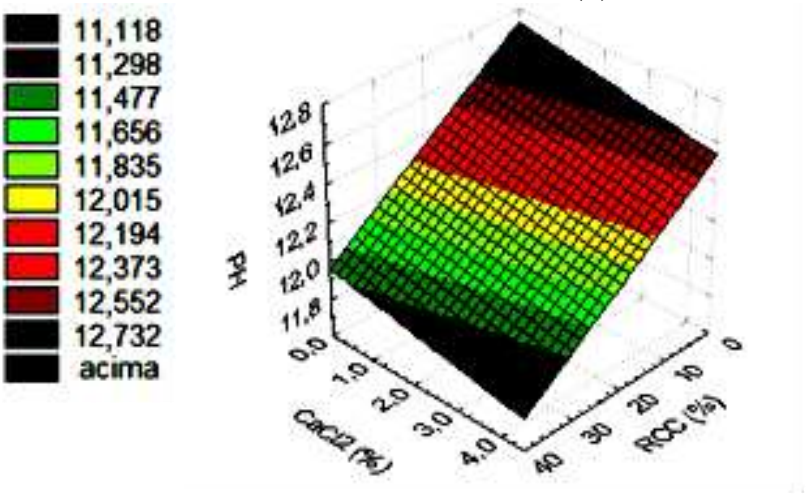

(f)

Figura 1: superfícies de resposta que correlacionam a variação do ph dos compósitos em função da substituição parcial do cimento e do teor de $\operatorname{cacl}_{2} \cdot 2 \mathrm{~h}_{2} \mathrm{o}$. (a) sílica ativa (b) metacaulim (c) cinza volante (d) escória de alto-forno (e) cinza de casca de arroz (f) resíduo de cerâmica. 


\section{DISCUSSÃO}

Analisando os valores de $\mathrm{pH}$ apresentados na Tabela 6, pode-se afirmar com 95\% de nível de confiança, que o pH dos compósitos produzidos com SA, variaram de 12,67 (Referência) para 11,40 (20\% de SA e 4,5\% de $\mathrm{CaCl}_{2} \cdot 2 \mathrm{H}_{2} \mathrm{O}$ ). Valores inferiores aos encontrados por outros autores [41,42,43]. A redução máxima de $10,02 \%$ parece pequena, em termos de valores porcentuais, mas lembrando que, conforme [43], a variação unitária do $\mathrm{pH}$ representa uma variação de 10 vezes da alcalinidade do meio, pode-se afirmar que a alcalinidade reduziu 12,7 vezes.

Os valores apresentados na Tabela 7 demonstram que o $\mathrm{pH}$ dos compósitos produzidos com substituições parciais do cimento por MK apresentaram reduções significativas a um nível de confiança de 95\%, variando de 12,67 (Referência) para 11,08 (40\% de $\mathrm{MK}$ e 4,5\% de $\mathrm{CaCl}_{2} \cdot 2 \mathrm{H}_{2} \mathrm{O}$ ). Valores, também, bem menores que os determinados em outras pesquisas [44,45]. A redução máxima verificada, representada por queda de $12,55 \%$ no valor do $\mathrm{pH}$, representa redução da alcalinidade do compósito de 19,2 vezes.

Na Tabela 8, são apresentados os valores determinados para o pH das solução do poro dos compósitos cimento-madeira produzidos com substituições parciais do cimento Portland por CV, também se pode observar reduções significativas da alcalinidade dos compósitos a 95\% de nível de confiança. As variações observadas foram de 12,67 (Referência) para valores para 12,02 ( $40 \%$ de $\mathrm{CV}$ e 4,5\% de $\mathrm{CaCl}_{2} \cdot 2 \mathrm{H}_{2} \mathrm{O}$ ), ou seja, redução máxima do $\mathrm{pH}$ da ordem de $5,13 \%$. Tal valor apresenta-se inferiores que os determinados por outros pesquisadores [42,46,47]. Em função dos valores determinados verifica-se que houve uma redução da alcalinidade do compósito de 6,5 vezes.

Na Tabela 9, pode-se perceber que o $\mathrm{pH}$ dos compósitos produzidos com substituições parciais do cimento por EAF apresentaram, também, reduções significativas a um nível de confiaça de $95 \%$, variando de 12,67 (Referência) para 12,18 (60\% de EAF e 4,5\% de $\mathrm{CaCl}_{2} .2 \mathrm{H}_{2} \mathrm{O}$ ), valores inferiores aos encontrados em pesquisas semelhantes [46]. Os valores determinados representam uma redução máxima de 3,87\% nos valores de $\mathrm{pH}$ dos compósitos, ou redução da alcalinidade de 4,9 vezes.

$\mathrm{Na}$ Tabela 10, os valores determinados para o $\mathrm{pH}$ dos compósitos cimento-madeira produzidos com substituições parciais do cimento Portland por CCA, também apresentam reduções significativas da alcalinidade a um nível de confiaçã de 95\%, apresentando variações entre 12,29 (10\% de CCA e $1 \%$ de $\left.\mathrm{CaCl}_{2} \cdot 2 \mathrm{H}_{2} \mathrm{O}\right)$ a $10,75\left(40 \%\right.$ de CCA e $4,5 \%$ de $\left.\mathrm{CaCl}_{2} \cdot 2 \mathrm{H}_{2} \mathrm{O}\right)$, valores, também inferiores que os determinados por outros autores $[42,46]$. Estes valores de pH representam redução percentual máxima de $15,15 \%$, ou seja, redução da alcalinidade de 19,2 vezes.

Na Tabela 11, são apresentados os valores determinados para o pH dos compósitos produzidos com substituições parciais do cimento Portland por RCC, também se pode observar reduções significativas da alcalinidade dos compósitos, variando de $12,30\left(10 \%\right.$ de $\mathrm{RCC}$ e $2 \%$ de $\left.\mathrm{CaCl}_{2} \cdot 2 \mathrm{H}_{2} \mathrm{O}\right)$ a $11,62(40 \%$ de RCC e $4,5 \%$ de $\mathrm{CaCl}_{2} \cdot 2 \mathrm{H}_{2} \mathrm{O}$ ). Valores inferiores que os determinados em pesquisas semelhantes [47]. Tais reduções do $\mathrm{pH}$ representam variação porcentual máxima de 8,29\%, ou redução da alcalinidade do compósito de 10,5 vezes.

Outra característica que pode ser observada nas Tabelas 5 a 11, diz respeito a valores estatisticamente diferentes, para o nível de confiança adotado, para mesmo teores de substituição do cimento Portland pelas pozolanas. Isso se deve a influência exercida pela adição de diferentes teores de $\mathrm{CaCl}_{2} \cdot 2 \mathrm{H}_{2} \mathrm{O}$ dentro de cada grupo de substituição do cimento pelas pozolanas. Quanto maiores os teores de $\mathrm{CaCl}_{2} \cdot 2 \mathrm{H}_{2} \mathrm{O}$, menores valores de $\mathrm{pH}$ foram determinados. Tal redução se deve a hidrólise salina, que pode ser explicada segundo as expressões:

$$
\begin{aligned}
& \mathrm{CaCl}_{2} \cdot 2 \mathrm{H}_{2} \mathrm{O} \rightarrow \mathrm{Ca}(\mathrm{OH})_{2}+2 \mathrm{HCl} \\
& \mathrm{Ca}(\mathrm{OH})_{2} \rightarrow \mathrm{Ca}^{2+}+2 \mathrm{OH}^{-} \\
& \mathrm{HCl} \rightarrow \mathrm{H}^{+}+\mathrm{Cl}^{-}
\end{aligned}
$$

Durante a hidrólise os íons positivos $\left(\mathrm{Ca}^{2+}\right)$ provenientes do $\mathrm{CaCl}_{2}$ imobilizam os íons $\mathrm{OH}^{-}$da água e liberam os íons $\mathrm{H}^{+}$, elevando a acidez do meio. Portanto, quanto maiores os teores de $\mathrm{CaCl}_{2}$, mais íons $\mathrm{H}^{+}$ serão liberados e menores pH serão determinados para o compósito.

\section{CONCLUSÕES}

O resíduo de Pinus spp. e as pozolanas estudadas neste trabalho apresentaram características que possibilitam sua utilização como aglomerado lignocelulósico e como substituições parciais do cimento Portland em compósitos cimento-madeira. Em relação ao compósito de Referência, que apresentou $\mathrm{pH}=12,67$, foram 
verificadas quedas significativas da alcalinidade dos compósitos estudados, em função da utilização das substituições parciais do cimento Portland, de 10,02\% (20\% de SA, com 4,5\% de $\mathrm{CaCl}_{2} .2 \mathrm{H}_{2} \mathrm{O}$ e $4,4 \%$ de SP), $12,55 \%$ (40\% de MK, com 4,5\% de $\mathrm{CaCl}_{2} .2 \mathrm{H}_{2} \mathrm{O}$ e $7,8 \%$ de $\mathrm{SP}$ ), $5,13 \%$ (40\% de $\mathrm{CV}$ com $4,5 \%$ de $\mathrm{CaCl}_{2} \cdot 2 \mathrm{H}_{2} \mathrm{O}$ ), $3,87 \%$ (60\% de EAF com $4,5 \%$ de $\mathrm{CaCl}_{2} \cdot 2 \mathrm{H}_{2} \mathrm{O}$ ), $15,15 \%$ (40\% de CCA, com $4,5 \%$ de $\mathrm{CaCl}_{2} .2 \mathrm{H}_{2} \mathrm{O}$ e $4,2 \%$ de SP) e $8,29 \%$ ( $40 \%$ de RCC, com 4,5\% de $\mathrm{CaCl}_{2} \cdot 2 \mathrm{H}_{2} \mathrm{O}$ e 2,6\% de SP). Foi constatado, também, a influência da utilização do aditivo acelerador de pega $\mathrm{CaCl}_{2} \cdot 2 \mathrm{H}_{2} \mathrm{O}$ sobre a alcalinidade dos compósitos, devido a hidrólise salina. A partir das equações de correlacionam a variação do $\mathrm{pH}$ dos compósitos com os teores de substituição do cimento Portland pelas pozonalas e pelo teor de $\mathrm{CaCl}_{2} \cdot 2 \mathrm{H}_{2} \mathrm{O}$ utilizados, podem ser determinados valores de substituição para reduções ainda maiores da alcalinidade das matrizes cimentícias e então analisada sua influência sobre as características físico-mecânicas e de durabilidade dos compósitos cimento-madeira.

\section{BIBLIOGRAFIA}

[1] SISTEMA NACIONAL DE INFORMAÇÕES FLORESTAIS - SNIF. Produção Florestal, disponível em: http://www.florestal.gov.br Acesso em: 16 out. 2016.

[2] DOUDART DE LA GREE, G.C.H., YU, Q.L., BROUWERS, H.J.H. "Wood-wool cement board: Utilization of a porous binder", Proceedings of the 14th International Inorganic-Bonded Fiber Composites Conference, p. 177- 186, 2014.

[3] SRUTHI, V., GEORGE, E.H. "A review on silica fume - An additive in concrete", International Journal of Innovative Research in Science. v.3, n.3, 2017.

[4] TASHIMA, M.M., FIORITI, C.F., AKASAKI, J.L., et al., "Cinza de casca de arroz (CCA) altamente reativa: método de produção e atividade pozolânica", Ambiente Construído, v.12, n.2, p. 151-163, 2012.

[5] INSTITUTO BRASILEIRO DE GEOGRAFIA E ESTATÍSTICA - IBGE. "Indicadores Conjunturais: Produção Agrícola", disponível em: http://www.ibge.gov.br Acesso em: 24 out. 2017.

[6] POUEY, M.T.F. "Beneficiamento da cinza de casca de arroz residual com vistas à produção de cimento composto e/ou pozolânico", Tese de Doutorado, Universidade Federal do Rio Grande do Sul, 320 p., 2006.

[7] INSTITUTO AÇO BRASIL - IAB. "Relatório de sustentabilidade 2016", disponível em: http://www.acobrasil.org.br/sustentabilidade/ . Acesso em 26 out. 2017.

[8] ALMARUZZAMAN, M. "A review on thr utilization of fly ash", Progress in Energy and Combustion Science, v.36, n.3, pp. 327-363, 2010.

[9] CARMO, J.B.M., PORTELLA, K.F. "Estudo comparativo do desempenho mecânico da sílica ativa e do metacaulim com adições químicas minerais em estruturas de concreto", Cerâmica, n. 54, pp. 309-319, 2008.

[10] GARCIA, E., CABRAL JÚNIOR, M., QUARCIONI, V.A., et al., "Resíduo de cerâmica vermelha (RCV): uma alternativa como material pozolânico", Cerâmica Industrial, v.19, n.4, pp. 31-38, 2015.

[11] HOPPE FILHO, J., GOBBI, A., PEREIRA, E., et al., "Atividade pozolânica de adições minerais para cimento Portland (Parte I): Índice de atividade pozolânica (IAP) com cal, difração de raios-x (DRX), termogravimetria (TG/DTG) e Chapelle modificado", Revista Matéria, v. 22, n.3, 2017.

[12] ASSOCIAÇÃO BRASILEIRA DE EMPRESAS DE LIMPEZA PÚBLICA E RESÍDUOS ESPECIAIS - ABRELPE. Panorama dos Resíduos Sólidos no Brasil 2016, disponível em: http://abrelpe.org.br/Panorama/panorama2016.pdf. Acesso em 06 jul. 2017.

[13] MATUELLA, M.F. "Efeitos da composição de resíduos de construção e demolição em seu comportamento mecânico para utilização em pavimentação", Dissertação de Mestrado, Universidade Federal do Rio Grande do Sul. 172 p, 2017.

[14] SOUZA, F.B., RAMOS NETTO, A.L., SILVA, D.S., et al., "Análise comparativa das propriedades de concretos convencionais com substituição parcial do cimento Portland por cinza de casca de arroz", Iniciação Científica, v.12, n.1, pp. 5- 18. 2014.

[15] BAROGHEL-BOUNY, V., CAPRA, B., LAURENS, S. Durabilidade das armaduras e do concreto de cobrimento, Durabilidade do Concreto, ed. São Paulo, Jean-Pierre Olliver e Angélique Vichot, pp. 255-326, 2014.

[16] ARDANUY, M., CLARAMUNT, J., TOLEDO FILHO, R.D. "Cellulosic fiber reinforced cement-based composites: A review of recent research", Construction and Building Materials, v.79, n.15, p. 115-128, 2015.

[17] MACÊDO, A. N., SOUZA, A. A. C., POMPEU NETO, B. B. "Chapas de cimento-madeira com resíduos da indústria madeireira da Região Amazônica", Ambiente Construído, v.12, n.2, p. 131-150, 2012. 
[18] NONAT, A. A hidratação dos cimentos, Durabilidade do Concreto, ed. São Paulo, IBRACON. p. 1740, 2014.

[19] MINISTÉRIO DO DESENVOLVIMENTO, INDÚSTRIA E COMÉRCIO EXTERIOR - MDIC. "Nota Técnica Plano Indústria, Subsetor Cimento", disponível em: http://www.abdi.com.br. Acesso em 14 dez. 2016.

[20] TITTELEIN, P., CLOUTIER, A., BISSONNETTE, B. "Design of a low-density wood-cement particleboard for interior wall finish", Cement and Concrete Composites, v.34, n.2, p. 218-222, 2012.

[21] FAN, M., NDIKONTAR, M.K., ZHOU, X., et al., "Cement-bonded composites made from tropical woods: Compability of wood and cement", Construction and Building Materials, n. 36, p. 135-140, 2012.

[22] SOTANNDE, O.A., OLUWADARE, A.O., OGEDOH, O., et al., "Evaluation as cement-bonded particleboard produced from Afzelia Africana wood residues", Journal of Engineering Science and Technology, v. 7, n. 6, p. 732-743, 2012.

[23] IWAKIRI, S., TRIANOSKI, R., CUNHA, A.B., et al., "Propriedades tecnológicas de painéis cimentomadeira produzidos com partículas de eucalipto", Revista de Ciências Agroveterinárias, v.14, n.3, p. 217223, 2015.

[24] BARACHO JÚNIOR, E. "Uso de resíduos lignocelulósicos na confecção de compósitos de cimento e areia para fins construtivos não estruturais”, Tese de Doutorado, Universidade Federal Rural de Pernambuco, 78 p., 2016.

[25] HAMOUDA, T., SEYAM, A.F.M., PETERS, K. "Evaluation of the integrity of 3D orthogonal woven composites with embedded polymer optical fibers", Composites Part B: Engineering, v. 78, pp. 79-85, 2015.

[26] TICHI, A.H., BAZYAR, B., KHADEMIESLAN, H., et al., "The effect of nano-wollastonite on biological, mechanical, physical and microstructural properties of the composite made of wood-cement fiber", Journal of Fundamental and Applied Sciences, v.8, n. 3S, pp. 1466-1479, 2016.

[27] BRASIL. Câmara Federal. Lei $\mathrm{n}^{\circ} 9055$ de $1^{\circ}$ de Junho de 1995. Disponível em: http://www.camara.gov.br/sileg/integras/513830.pdf Acesso em 07 set. 2017.

[28] NA, B., WANG, Z., WANG, H., et al., "Wood-cement compability review", Wood Research, v. 59, n. 5, pp. 813-826, 2014.

[29] LIMA, A.J.M., IWAKIRI, S., LOMELÍ-RAMIREZ, M.G. "Study of the interaction of Portland cement and Pinus wood for composites using Bragg sensors in optical fibers", BioResources, n.10, v. 4, p. 66906704, 2015.

[30] CABRAL, M.R., FIORELLI, J., SAVASTANO JÚNIOR, H., et al., "Study of the potential use of the sugarcane bagasse in cement-panels", In: Proceedings of the International Conference on Composite Science and Technology, Lisbon, 2015.

[31] DIAZ, J. P. V. "Comportamento mecânico de compósitos cimentícios reforçados com fibras de pupunha", Dissertação de Mestrado, Pontifícia Universidade Católica do Rio de Janeiro, Rio de Janeiro, 147 p., 2016.

[32] MOHR, B.J. "Durability of pulp fiber-cement composites", PHD Thesis, Georgia Institute of Technology, Atlanta, 227 p., 2005.

[33] ASSOCIAÇÃO BRASILEIRA DE NORMAS TÉCNICAS - ABNT. NBR NM 52: Agregado miúdo Determinação da massa específica e massa específica aparente. Rio de Janeiro, 2009.

[34] ASSOCIAÇÃO BRASILEIRA DE NORMAS TÉCNICAS - ABNT. NBR 7190: Projeto de estruturas de madeira. Rio de Janeiro, 1997.

[35] ASSOCIAÇÃO BRASILEIRA DE NORMAS TÉCNICAS - ABNT. NBR NM 248: Agregados Determinação da composição granulométrica. Rio de Janeiro, 2003.

[36] TECHNICAL ASSOCIATION OF THE PULP AND PAPER INDUSTRY - TAPPI. TAPPI T 204 CM: Solvent extractives of wood and pulp, 2017.

[37] TECHNICAL ASSOCIATION OF THE PULP AND PAPER INDUSTRY - TAPPI. TAPPI T 252 OM: $\mathrm{pH}$ and electrical conductivity as hot water extracts of pulp, paper and paperboard, 2016.

[38] PAIVA, P.A. "Metodologia de superfície de resposta e análise de componentes principais em otimização de processos de manufatura com múltiplas respostas correlacionadas", Tese de Doutorado, Universidade Federal de Itajubá, Itajubá, 229 p., 2006. 
[39] MOSLEMI, A.A.;PFISTER, S.C. "The influence of cement/wood ratio and cement type on bending strength and dimensional stability of wood-cement composite panels", Wood and Fiber Science, v. 19, n. 2, pp. 165-175, 1987.

[40] ASSOCIAÇÃO BRASILEIRA DE NORMAS TÉCNICAS - ABNT. NBR 7215: Cimento Portland Determinação da resistência à compressão. Rio de Janeiro, 2009.

[41] BYFORS, K. "Influence of silica fume and fly ash on chloride diffusion and pH values in cement paste", Cement and Concrete Research, v. 17, n.1, pp. 115-130, 1987.

[42] CERVO, T. C. "Influência da finura e do teor de pozolana na penetração de cloretos e na solução aquosa dos poros do concreto", Dissertação de Mestrado, Universidade Federal de Santa Maria, 129 p., 2001.

[43] ORTOLAN, V. K. "Avaliação da influência do pH e da força iônica da solução dos poros do concreto na resistência à corrosão da armadura”, Dissertação de Mestrado, Universidade do Vale dos Sinos, 128 p., 2015.

[44] COLEMAN, N.J., PAGE, C.L. "Aspects of the pore solution chemistry of hydrated cement pastes containing metakaolin", Ceramic and Concrete Research, v.27, n.1, pp. 147-154, 1997.

[45] OLIVEIRA, C.A.S. "Avaliação microestrutural e comportamento físico e mecânico de concretos de alto desempenho produzidos com metacaulim", Tese de Doutorado, Universidade Federal de Minas Gerais, Belo Horizonte, 196 p., 2007.

[46] DAL RI, M. "Efeitos da adição de cal hidratada em concretos em altos teores de adição mineral na penetração de cloretos e na solução aquosa dos poros do concreto", Dissertação de Mestrado, Universidade Federal de Santa Maria, 111 p., 2002.

[47] JERÔNIMO, K.L. "Estudo da durabilidade de concretos com adição de resíduos da indústria da cerâmica vermelha com foco na corrosão das armaduras", Tese de Doutorado, Universidade Federal do Rio Grande do Sul. Rio Grande do Sul, 207 p., 2014.

\section{ORCID}

Adauto José Miranda de Lima

Setsuo Iwakiri

https://orcid.org/0000-0001-6921-6609

https://orcid.org/0000-0003-0390-3830 